\title{
AN EFFICIENT STORM SURGE FORECASTING TOOL FOR COASTAL MISSISSIPPI
}

\author{
Himangshu S. Das ${ }^{1}$, Hoonshin Jung ${ }^{3}$, Bruce Ebersole², Ty Wamsley², and Robert W. Whalin ${ }^{1,3}$ \\ Coupled storm surge simulations with fine resolution have become a reality due to the rapid development of \\ computer power and advancement in the integration of the simulation models. However, the real-time application of \\ such robust simulations is often constrained by the availability of time and computational resources. In this study, an \\ alternative, Storm Surge Forecasting Tool (SSFT) has been developed to forecast storm surge in Coastal Mississippi. \\ The algorithm of SSFT uses a weight based Storm Similarity Index (SSI) that is defined by current hurricane position \\ Central Pressure $\left(C_{P}\right)$, Pressure Scale Radius $\left(R_{\max }\right)$ along with hurricane track, landfall location, storm forward \\ speed, and forecasted storm track published by the National Hurricane Centre (NHC) and correlated with the \\ characteristics of synthetic storms within the underlying database. Based on the values of SSI (scales from 0 to 1), the \\ SSFT identifies a group of storms that much as close as possible with the characteristics of the approaching \\ hurricanes and then display high resolution simulation results (e.g., maximum surge elevation and hydrographs). The \\ SSFT model operates in two different modes:1) Hindcasting mode and 2) Forecasting mode. The SSFT GUI was \\ tested in both modes and we found that the method is very promising. Using this tool and approach as a decision \\ aide, the emergency personnel can quickly forecast local storm surge along the coast of Mississippi. This will allow \\ them to make quantitative and objective decisions by evaluating "what-if-scenarios" starting two to three days ahead \\ of the landfall.
}

Keywords: storm surge forecasting; emergency management; hurricane; coastal Mississippi

\section{INTRODUCTION}

The simulation and prediction of storm surge are intrinsically complex due to the non-linear interaction between currents, winds and waves. One of the prevalent methods to predict the storm surge and associated risks is to use an integrated, coupled forecasting system for tides, winds and waves. Multi-scale and coupled storm surge simulations with fine resolution have become a reality due to the rapid development of computational power and advancement in the integration of the simulation models. Various storm surge models (i.e., SLOSH, CH3D-SSMS, ADCIRC) have been developed and used in real-time for estimating storm surge from an approaching hurricane. However, the applications of process based and coupled simulations are often constrained by the fact that execution of such numerical models is complex and often time consuming.

Once a hurricane is developed in the Atlantic or Pacific oceans, the United States National Hurricane Center (NHC) releases hurricane advisory data every 6 hours. When a new hurricane advisory is released, decision makers and emergency managers need crucial information such as extent and timing of storm surge with sufficient accuracy ahead of the actual event. In recent years, several techniques have been used to provide such crucial information. One of the techniques is to run a storm surge model such as ADCIRC using hundreds of computers (or CPUs) in parallel and use a hotstart concept where the model simulation starts from the nowcast point representing current conditions (Fleming et al. 2007). Other forecasting systems use simple equations to reduce computational time for preparing the input data. For example, using the synthetic asymmetric vortex and wind forcing model (Holland model; Holland 1980) allows the surge forecasting model to use surface wind and pressure data without waiting several hours to get these wind data from the National Center for Environmental Prediction (NCEP) model (Mattocks \& Forbes, 2008). Even with such various efforts, it can take hours to forecast storm surge in real time once a hurricane advisory is issued from NHC.

To address these limitations, we have developed and verified an alternative, efficient and robust data oriented technique to forecast storm surge in coastal areas. The developed Storm Surge Forecasting Tool (SSFT) can be used to forecast the extent of storm surge (e.g., maximum surge elevation, inundation area, surface wind and wave field) as well as details of how the storm surge will evolve with time. With the help of this tool, decision makers and emergency managers can quickly assess the impact of an approaching hurricane and make objective decisions by evaluating what-ifscenarios quickly following each NHC advisory and starting two to three days ahead of landfall.

\footnotetext{
${ }^{1}$ Dept. of Civil and Environmental Engineering, Jackson State University, 1400 Lynch St, Jackson, MS 39217, USA

${ }^{2}$ Coastal and Hydraulics Laboratory, U.S. Army Engineer Research and Development Center, 3909 Halls Ferry Rd., Vicksburg, MS 39180, USA

${ }^{3}$ NDCIEM, Mississippi E-Center, 1230 Raymond Road. Jackson, MS 39204, USA
} 


\section{DATA AND METHOD \\ Data}

During 2007-08, Federal Emergency Management Agency, Region Six (FEMA-R6) and the United States Army Corps of Engineers (USACE) conducted two separate studies to identify flood frequencies for Eastern Louisiana and three coastal counties of Mississippi (Resio et al. 2007; Niedoroda et al. 2010). Characteristics of the historical hurricanes were synthesized by storm frequency of occurrence, landfall track azimuth, central pressure deficit, pressure scale radius, forward speed of the storm and landfall position. Based on these hurricane characteristics, an optimum sampling method was developed using joint probability methods to find a set of hypothetical synthetic storms to represent the full range of conditions contained in the historic storm population. From this statistical analysis, two different groups of storms, Group-1 storms [pressure scale deficit $\Delta \mathrm{P}>48 \mathrm{mb}$ ] and Group-2 storms $[\Delta \mathrm{P}=31$ to $48 \mathrm{mb}$ ], were identified (Niedoroda et al., 2010). Each of the synthetic storms was then offset by a distance of one radius to maximum wind from the landfall location, creating multiple offset synthetic tracks that covered the entire length of the Mississippi coast. Thus, for the FEMA-R6 study, 228 synthetic storms represented by a unique combination of track, intensity, forward speed, storm size and radial wind profile decay were considered. Figure 1(a) shows the track distribution of the synthetic storms used in the FEMA-R6 study. A similar approach was also used by the USACE to develop flood frequency for Eastern Louisiana. USACE developed 47 synthetic storms which were representative to the coast of Eastern Louisiana. Figure 1(b) shows the storm tracks used in the USACE study. Each of the synthetic storms was simulated using the ADvanced CIRCulation Model (ADCIRC) [Westerink and Luettich, 1991]. All model results of the combined 275 synthetic storms were then archived as part of the present study.

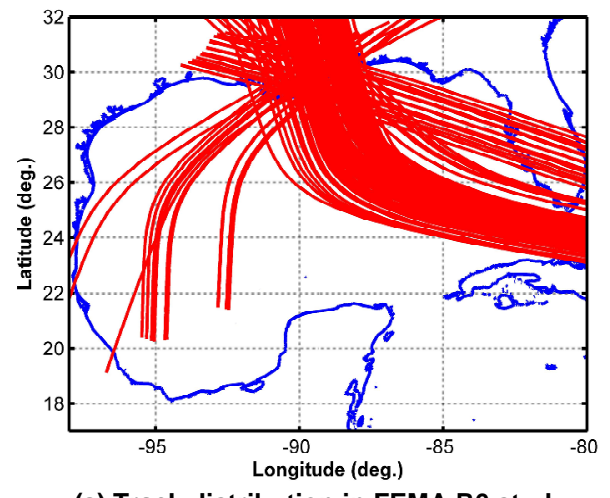

(a) Track distribution in FEMA-R6 study

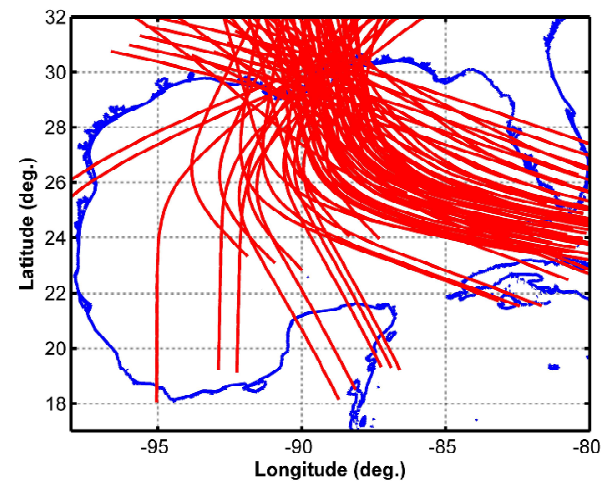

(b) Track distribution in USACE study

Figure 1: The distribution of storm tracks

\section{Method}

In this study, we have developed a Storm Surge Forecasting Toolbox (SSFT) which is a Graphical User Interface (GUI) written in MATLAB. The GUI accesses the archived 275 synthetic storm simulations organized in a database. The SSFT GUI operates in two different modes: a) Hindcasting mode and b) Forecasting mode. The hindcasting mode operates to validate the storm surge model by comparing simulation results with observed High Water Marks (HWM) from historical storms (e.g., Camille and Katrina) that made landfall close to Mississippi. In the forecasting mode, the model automatically extracts current hurricane information (e.g., current location, central pressure and radius to maximum wind) from the NHC website and identifies best matching synthetic storms by establishing a correlation between the approaching hurricane and synthetic storms within the database.

In the hindcasting mode, model validations are achieved by extracting key parameters of the representative historical hurricanes from the Best Track information available at the NHC website and then comparing those parameters with the synthetic storms archived in the database of the SSFT. In the current GUI, three main parameters are compared which are: 1) Landfall location $\left.\left(\mathrm{S}_{\mathrm{LF}}\right), 2\right)$ Central pressure deficit $\left(\mathrm{C}_{\mathrm{p}}\right)$ and 3) Pressure scale Radius $\left(\mathrm{R}_{\max }\right)$. The $\mathrm{C}_{\mathrm{p}}$ and $\mathrm{R}_{\mathrm{Max}}$ parameters are compared at an offshore location which corresponds to the storm position at a time 8 hours ahead of the landfall (Niedoroda et al. 2010). With these three major storm parameters, and by comparing available HWMs associated with the representative historical storms and ADCIRC simulation results within the SSFT 
database, the GUI then extracts the best matching synthetic storm. The flow chart of operation in the hindcasting mode is shown in Figure 2(a).

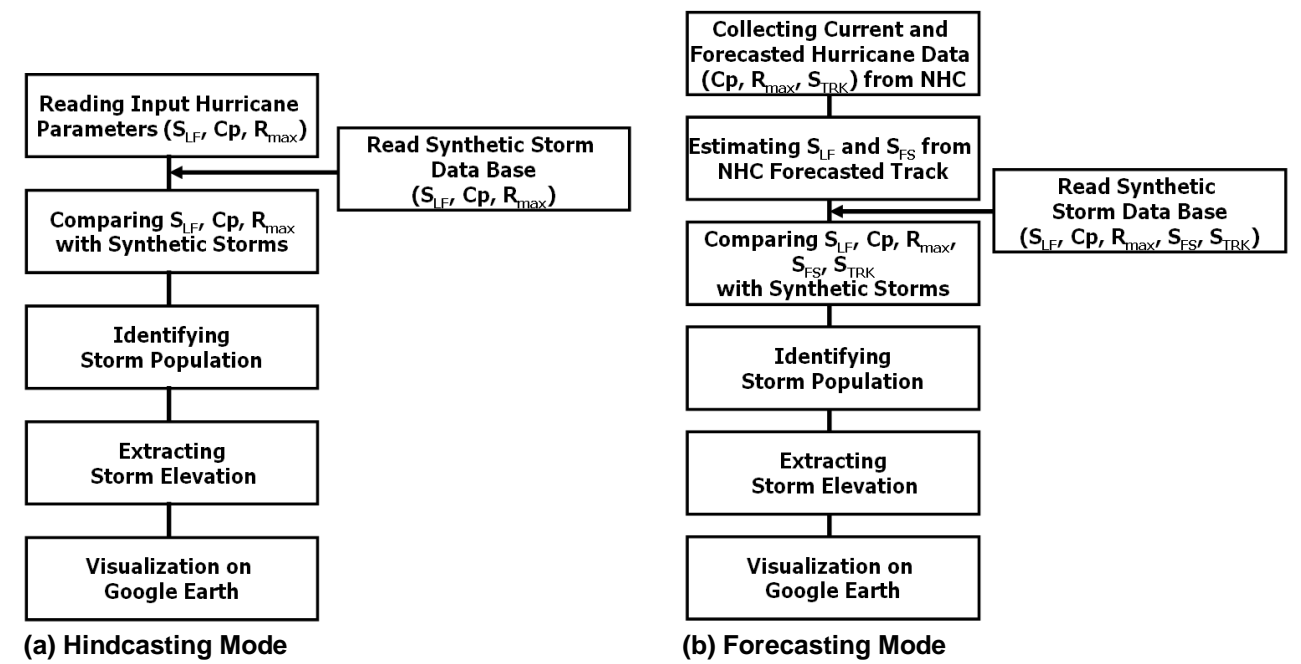

Figure 2. Flowchart of the SSFT GUI (a) Hindcasting mode and (b) Forecasting mode

Figure 2(b) shows the calculation process in forecasting mode. At first, the SSFT GUI collects current hurricane information by accessing the Automated Tropical Cyclone Forecast (ATCF) database provided by the National Hurricane Center (NHC). Since 2008, the NHC website has been providing real time GIS coverage of the forecast advisory such as five day hurricane cone. This GIS data from NHC are utilized by the SSFT GUI. The ATCF site also provides possible hurricane tracks and with maximum sustained wind speed at specific intervals (typically every 6 hours) starting 5 to 7 days ahead of the landfall. In our approach, the real time GIS data from NHC is used to determine the projected landfall location $\left(\mathrm{S}_{\mathrm{LF}}\right)$ and the characteristic forward speed $\left(\mathrm{S}_{\mathrm{FS}}\right)$, and storm track $\left(\mathrm{S}_{\mathrm{TRK}}\right)$ of the approaching hurricane. The central pressure $(\mathrm{Cp})$ and radius to maximum wind $\left(\mathrm{R}_{\max }\right)$ values at the current location are also extracted from the NHC official forecast site (ftp//:ftp.nhc.noaa.gov/atcf/afst/). Normally, the NHC releases real time data, such as position, $\mathrm{Cp}$, and $\mathrm{R}_{\max }$ as well as the $\mathrm{S}_{\mathrm{TRK}}$ with cone of uncertainty of an approaching hurricane developed in the Northern Atlantic Basin starting 5 to 7 days ahead of the landfall. The forward speed $\left(\mathrm{S}_{\mathrm{FS}}\right)$ is estimated by using the information available for the forecasted hurricane track. The evolution and development of the forecasted track from the NHC along with the information of key parameters allow the SSFT GUI to compare with the characteristics of the synthetic storm parameters archived in the database. The SSFT then identifies a group of storms that best matches with the track distribution and characteristics of the approaching hurricane. In the forecasting mode, the SSFT uses a weight based Storm Similarity Index (SSI) to identify the best matching synthetic storm by correlating hurricane characteristic parameters at a current hurricane position and estimated landfall location with the characteristics of the synthetic storms within the underlying database. The calculation method is shown in Figure 3. The SSI ranges from 0 to 1 and is calculated by the following:

$$
S S I=\left(a \cdot H_{L F}+b \cdot H_{C p}+c \cdot H_{R \max }+d \cdot H_{F S}\right) \cdot H_{T R K}
$$

where, $\mathrm{H}_{\mathrm{LF}}=$ parameter indicating landfall similarity $(0$ to 1$) ; \mathrm{H}_{\mathrm{Cp}}=$ central pressure deficit similarity $(0$ to 1$) ; \mathrm{H}_{\mathrm{Rmax}}=$ pressure scale radius similarity (0 to 1$) ; \mathrm{H}_{\mathrm{FS}}=$ storm forwarding speed similarity (0 to 1$)$; $\mathrm{H}_{\mathrm{TRK}}=$ storm track similarity $(0$ or 1$)$, which indicates the similarity for forward direction of a hurricane. Here, $a, b, c$, and $d=$ weighting factor whose summation is one. In the present toolbox, fixed values of $a, b, c$ and $d$ were used which were $0.4,0.3,0.2$ and 0.1 respectively. These values need to be optimized. 


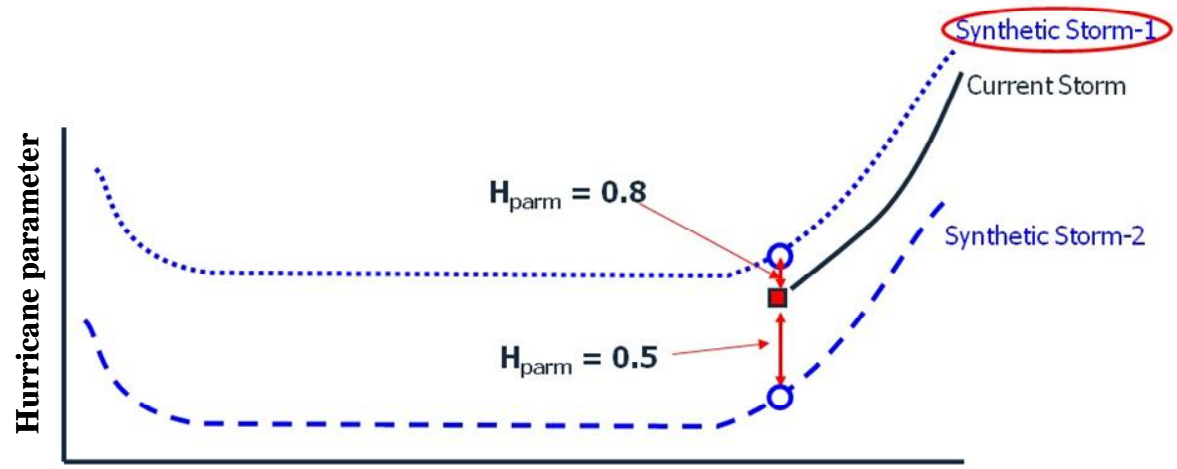

Distance from Landfall

Figure 3. Schematic diagram of process how the SSFT GUI identifies the best matching synthetic storm by correlating hurricane parameters at current location. The model computes the deviation of the selected 4 hurricane parameters and then scales them between 0 and 1. Model then identifies which synthetic storms are close to the current storm.

This process starts with calculating SSI values by correlating current hurricane position, $\mathrm{Cp}$ and $\mathrm{R}_{\max }$ values along with the forecasted track and landfall location $\left(\mathrm{S}_{\mathrm{LF}}\right)$ with the characteristics of the synthetic storms. Based on the SSI, the toolbox then identifies a group of storms that match, as close as possible, with the characteristics of the approaching hurricane and then displays ADCIRC simulation results (e.g., maximum surge elevation and hydrographs at specific locations) in Google Earth environment. This is a very fast process, taking only about 2 to 3 minutes on a regular PC to forecast high resolution storm surge in coastal Mississippi once an advisory is issued by the NHC. As mentioned earlier, NHC advisories are issued every 6 hours (ftp.nhc.noaa.gov) starting 6-7 days ahead of the projected landfall. However, the current SSFT GUI can only be used once the hurricane enters the Gulf of Mexico and can be operational typically 2-3 days ahead of the landfall. Once an advisory is issued at the NHC, the SSFT GUI operates in an autonomous mode extracting key data from the advisory, and then comparing those with the synthetic storms in the database and then displaying key results such as extent and height of storm surge with hydrographs in Google Earth. The operation repeats itself once a new advisory is issued at the NHC website.

\section{RESULTS}

\section{Hindcasting Mode}

For validation, we compared model results with the observed High Water Marks (HWMs) from historical hurricanes including hurricanes Camille (1969) and Katrina (2005) that made landfall on the Mississippi coast. As mentioned earlier, three parameters (i.e., $\mathrm{S}_{\mathrm{LF}}, \mathrm{Cp}$, and $\mathrm{R}_{\max }$ ) were used as input to the SSFT GUI to validate model. These three input parameters were extracted from the Best Track Information available at the NHC archived database. The SSFT was able to quickly identify the best matching storms, which was JOS6016D for hurricane Camille and JOS6018D for hurricane Katrina stored in the database. Table 1 shows the input parameters to the SSFT GUI and results of the matching synthetic storms for hurricane Camille and Katrina. Figure 4 shows the tracks for Hurricane Camille and Katrina with the best matching synthetic storms. The comparison of observed HWMs and model simulation results are shown in Figure 5.

Table 1. Input values of hurricane parameters (landfall location and $\mathrm{Cp}$ and Rmax at -8 hour before landfall) for Hurricane Camille and Katrina and result of the best matching synthetic storms.

\begin{tabular}{|c|c|c|c|c|c|c|c|}
\hline \multicolumn{4}{|c|}{ Input Parameters } & \multicolumn{4}{c|}{ Results } \\
\hline Name & $\begin{array}{c}\text { Landfall } \\
\left(\text { lat/lon, }{ }^{\circ}\right)\end{array}$ & $\begin{array}{c}\mathrm{Cp} \\
(\mathrm{mb})\end{array}$ & $\begin{array}{c}\mathrm{R}_{\max } \\
(\mathrm{nm})\end{array}$ & Name & $\begin{array}{c}\text { Landfall } \\
\left(\text { lat/lon, }{ }^{\circ}\right)\end{array}$ & $\begin{array}{c}\text { Cp } \\
(\mathrm{mb})\end{array}$ & $\begin{array}{c}\mathrm{R}_{\max } \\
(\mathrm{nm})\end{array}$ \\
\hline Camille & $30.3 /-89.2$ & 905 & 8 & JOS6016D & $30.1 /-89.4$ & 909 & 7.3 \\
\hline Katrina & $29.3 /-89.6$ & 905 & 20 & JOS6018D & $29.9 /-89.4$ & 910 & 14.5 \\
\hline
\end{tabular}




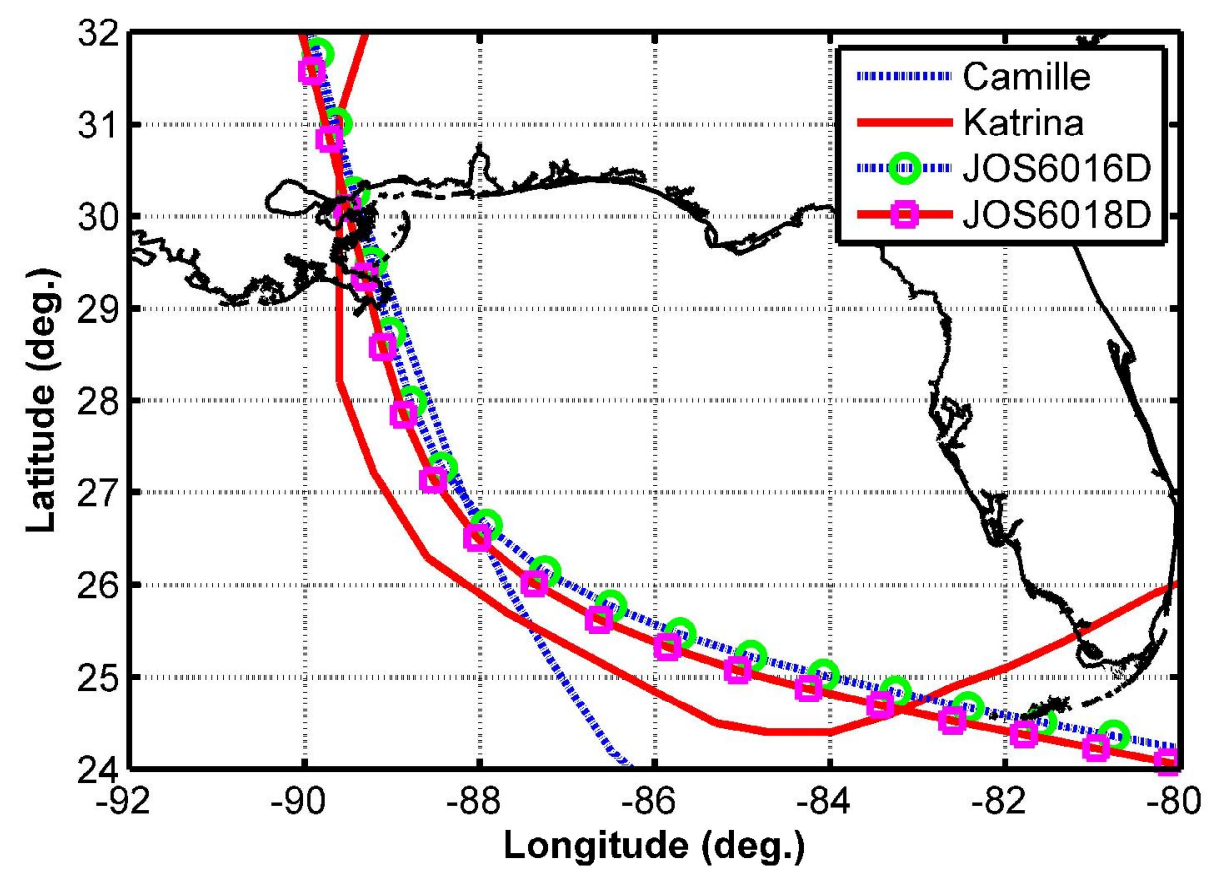

Figure 4: Track of Hurricane Camille and Katrina and the best matching synthetic storms (JOS6016D for Camille and JOS6018D for Katrina).

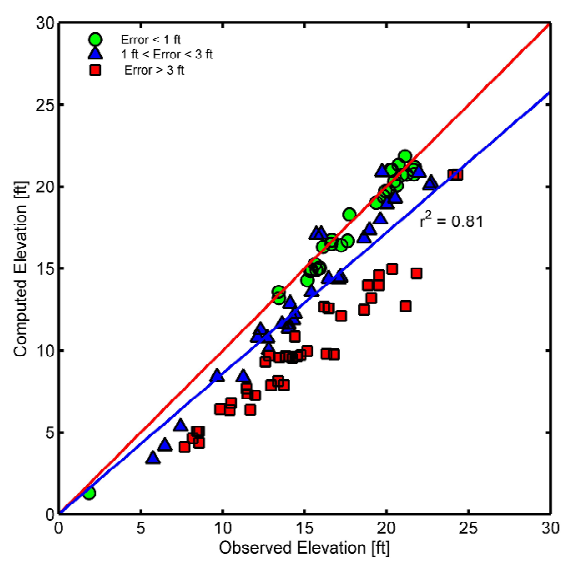

(a) Hurricane Camille

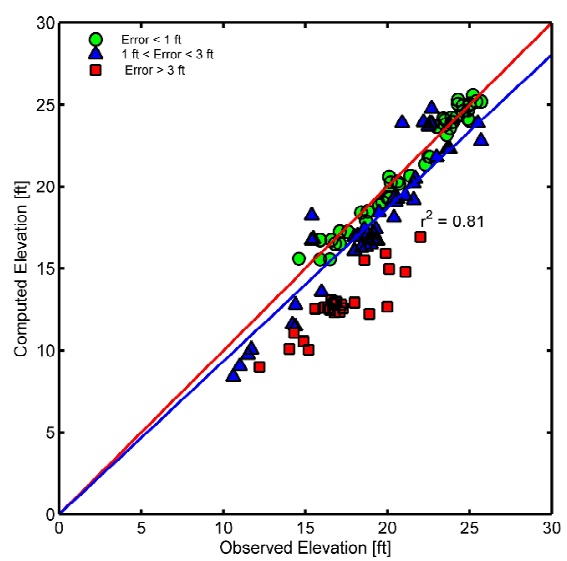

(b) Hurricane Katrina

Figure 5: The comparison between Observed and Predicted High Water Marks (a) for hurricane Camille (b) for hurricane Katrina. In these figures, red lines represent $\mathbf{4 5}$ degree line whereas, blue lines are obtained by regression analyses.

The comparison results with observed HWMs show that the SSFT performs satisfactorily in hindcasting historical storms. The correlation between observed and modeled high water marks were reasonable $\left(\mathrm{R}^{2}=0.81\right.$ for both Katrina and Camille).

While running the toolbox in hindcasting mode, we verified that the parameters having the greatest potential for variation in storm surge are landfall location, radius of maximum winds, forward speed, and central barometric pressure. We also observed that slight variations in one or a combination of those parameters may result in significant changes in the resultant storm surge. From this, we hypothesized that in order to improve the SSFT performance, the database must incorporate additional 
information representing those historical storms (such as hurricane Camille and Katrina). To test the hypothesis, we ran 6 more ADCIRC simulations ( 3 for hurricane Camille and 3 for hurricane Katrina) with meteorological (track, wind and pressure field) inputs that are close to information available at the NHC best track database. These simulations were then added to the central database. The SSFT was rerun in the hindcasting mode to compare with the HWMs. Figure 6 shows the improved results. In Figure 6(a) the red line shows the actual Camille track and the blue line shows the track of synthetic storm. Also, in this figure, color symbols represent the error between the observed and simulated surge elevations at the HWM locations. Note that while using the original database, JOS6016D was found to be the most appropriate to Camille. But due to the fact that the track of JOS6016D was slightly to the west of the actual Camille track, significant model errors were observed, especially near the right side of the landfall. This is shown in Figure 6(a) with red squares representing absolute errors greater than 3 ft. However, model results significantly improved with added synthetic storms with their tracks very close to the actual track [Figure 6(b)]. This demonstrates the need for additional pre-computed simulation results with fine intervals in the synthetic storm parameters. Therefore, the relatively poor correlations with observed HWMs for Hurricane Camille and Katrina may be supplemented with additional synthetic storms with better storm parameterizations.

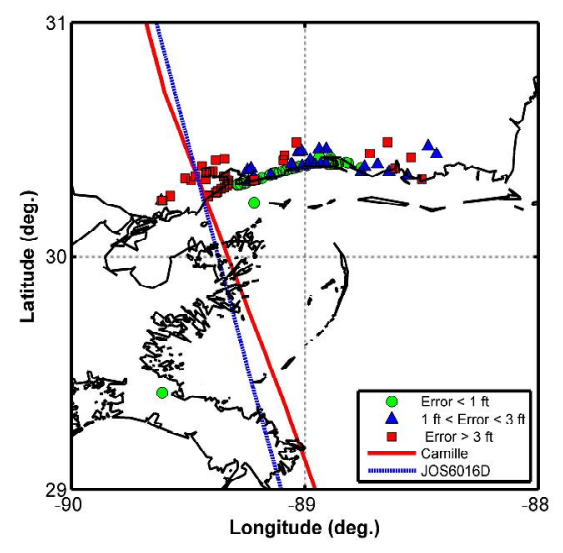

(a) Camille VS. JOS6016D

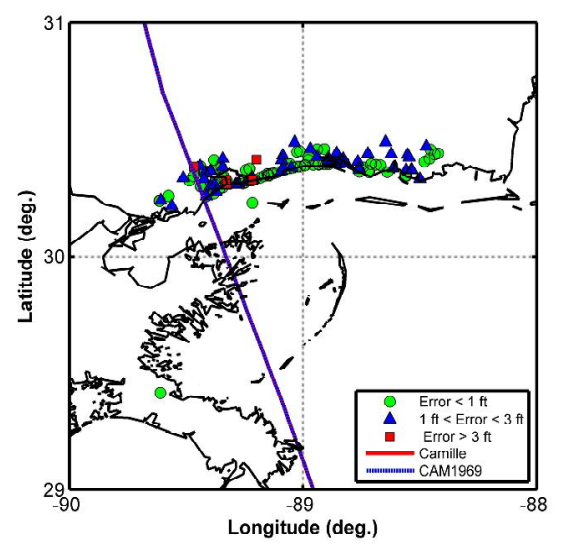

(b) Camille VS. CAM1969

Figure 6: Improvement of Hurricane Camille validation. (a) Comparison between observed and model HWM using original database (b) Improved model results with revised database (Hurricane Camille track line is exactly overlapped by the CAM1969 storm track).

\section{Forecasting Mode}

In order to evaluate how the SSFT performs in forecasting mode, the real time advisory data issued during hurricane Gustav (August 29-31, 2008) were used. Two advisory data sets (al072008-5day020A, and al072008-5day-027A; herein, referred as advisory numbers 20 and 27) were chosen. Each data set had the projected hurricane track along with current storm location, $\mathrm{Cp}$ and $\mathrm{R}_{\max }$ values. Figure 7 shows the NHC forecasted Hurricane Gustav tracks and cone of uncertainty for advisory numbers 20 and 27. Figure 7 also shows the best matching synthetic storms with highest Storm Similarity Index (SSI) values. It can be seen that for the NHC advisory number 20, synthetic storm JOS6003A had the highest SSI (0.84), whereas, for the advisory number 27 , the SSI was updated and synthetic storm JOS6001A was found to be the best matching synthetic storm for the current Hurricane Gustav. Table 2 summarizes the results identifying the group of storms with high SSI values for the two advisories. Note that, due to huge changes in the Cp values from advisory number 20 to 27 (980 mb reduced to $958 \mathrm{mb}$ ), a new set of synthetic storms were identified by the SSFT. The model results for each advisory data were then compared with the observed HWMs for hurricane Gustav (Figure 8). In general, the model surge elevations extracted from JOS6001A storm are in a reasonable agreement with the observed $\operatorname{HWM}(\mathrm{s})$. The lower correlation results for Gustav might occur for two reasons, (1) hurricane Gustav made landfall in the Louisiana coast and (2) the current database of the SSFT is impaired with a storm population that concentrates only on the Mississippi coast. Nevertheless, even with the limitations of 
the current database, the application of the current methodology is promising. Additional resolution in the underlying database can be easily achieved via additional storm simulations.

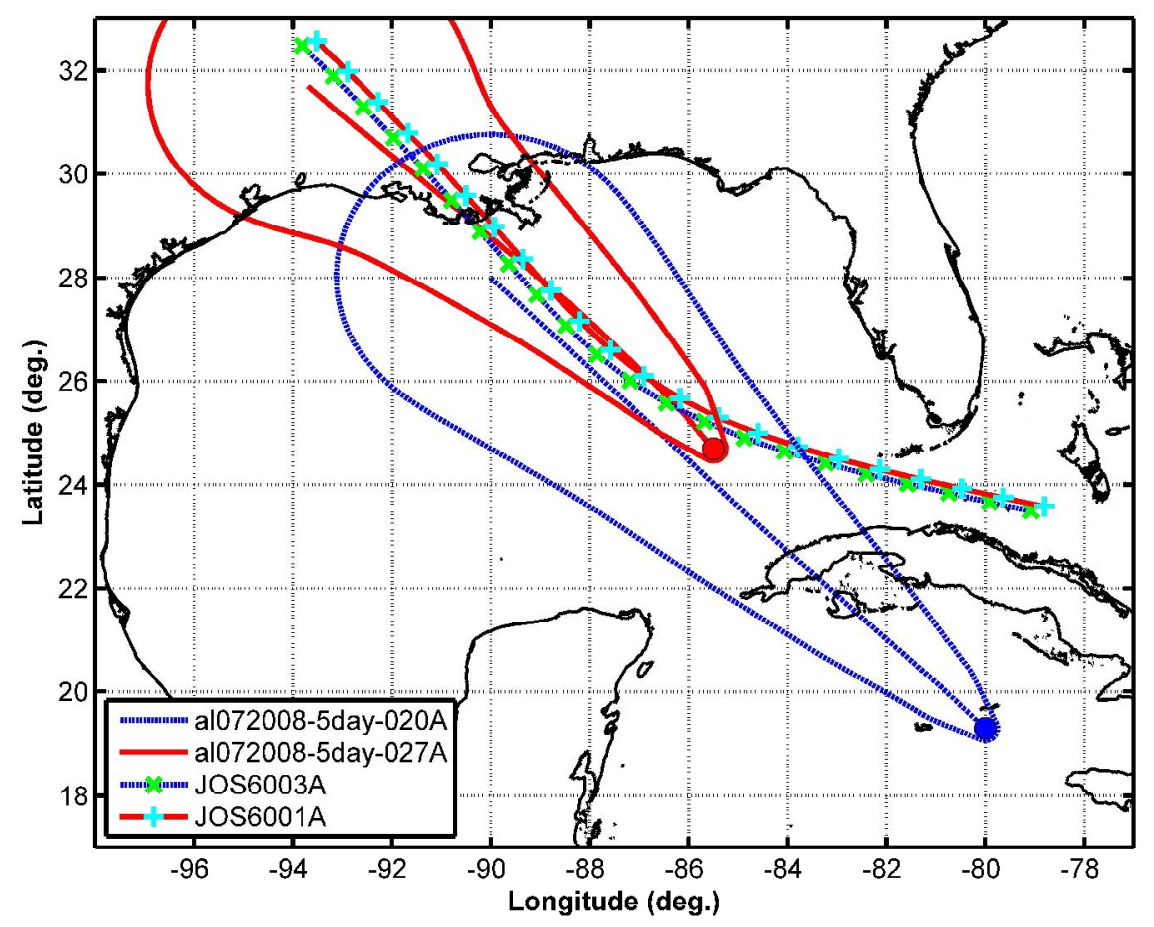

Figure 7: Forecasted Hurricane Gustav tracks (Advisory Number 20 and 27) and synthetic storm tracks having the highest SSI values (JOS6003A synthetic storm for Advisory Number 20 and JOS6001A storm for Advisory Number 27). The red and blue dots (0) indicate the current hurricane location.

\begin{tabular}{|c|c|c|c|c|}
\hline Advisory Number & \multicolumn{2}{|c|}{ al072008_5day_020A } & \multicolumn{2}{|c|}{ al072008_5day_027A } \\
\hline Date & \multicolumn{2}{|c|}{ 08/30/00:00 } & \multicolumn{2}{|c|}{$08 / 31 / 12: 00$} \\
\hline Location (Lat/Long; ${ }^{\circ}$ ) & \multicolumn{2}{|c|}{$19.3 /-80.0$} & \multicolumn{2}{|c|}{$29.1 /-90.4$} \\
\hline Current $C_{p}(\mathrm{mb})$ & \multicolumn{2}{|l|}{980} & \multicolumn{2}{|l|}{958} \\
\hline Current $R_{d}(n m)$ & \multicolumn{2}{|l|}{20} & \multicolumn{2}{|l|}{15} \\
\hline $\begin{array}{c}\text { Projected Landfall Location } \\
\left(\text { Lat/Long; }{ }^{\circ}\right)\end{array}$ & \multicolumn{2}{|c|}{ 29.1/-91.0 } & \multicolumn{2}{|c|}{ 29.1/-90.4 } \\
\hline & Synthetic Storm & SSI & Synthetic Storm & SSI \\
\hline Results & $\begin{array}{l}\text { JOS6003A } \\
\text { JOS6001A } \\
\text { JOS6011A } \\
\text { CAT2008A } \\
\text { JOS6003B } \\
\text { CAT2008B }\end{array}$ & $\begin{array}{l}0.84 \\
0.80 \\
0.78 \\
0.77 \\
0.75 \\
0.71 \\
\end{array}$ & $\begin{array}{l}\text { JOS6001A } \\
\text { CAT2008A } \\
\text { JOS6001B } \\
\text { CAT2008B } \\
\text { JOS6004A } \\
\text { CAT2008C }\end{array}$ & $\begin{array}{l}0.82 \\
0.78 \\
0.73 \\
0.72 \\
0.71 \\
0.63\end{array}$ \\
\hline
\end{tabular}




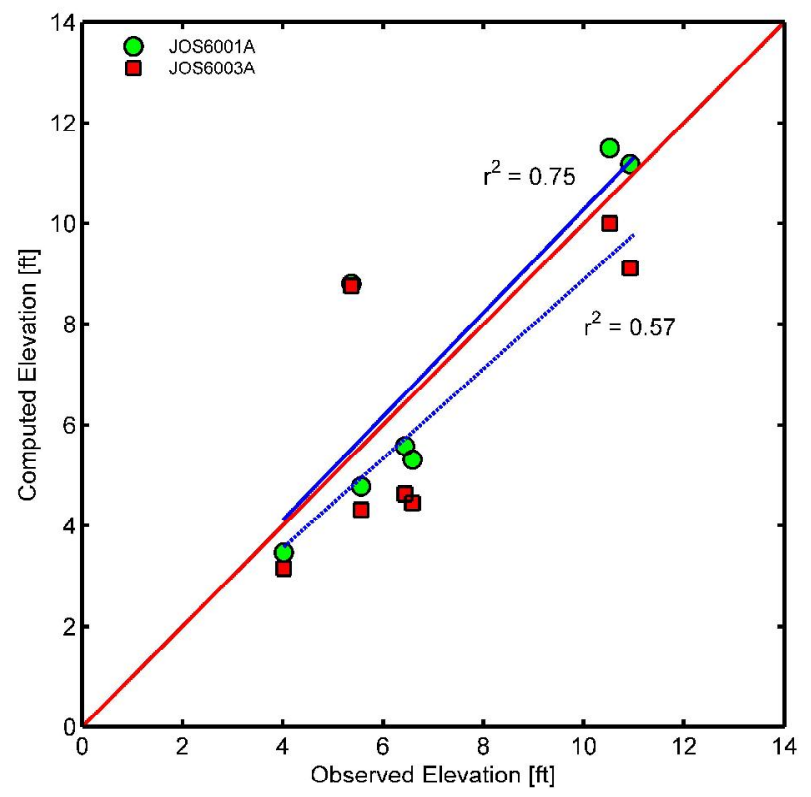

Figure 8: The comparison between observed HWMs for Hurricane Gustav and model results (JOS6003A for advisory number 20 [in red $\mathrm{m}$ ] and JOS6001A for advisory number 27 [in green $\bullet$ ].

\section{DISCUSSION AND CONCLUSION}

A method to predict storm surge heights using an efficient data oriented approach has been developed. The SSFT GUI operates both in hindcasting and forecasting mode. For both modes, the SSFT GUI was tested against historical hurricanes (for hurricanes Camille and Katrina in hindcasting mode and hurricane Gustav in forecasting mode). The SSFT was able to quickly identify the best matching synthetic storms in both cases which makes the approach very efficient and robust. However, in order to improve the forecasting results, further scientific enhancements are required. In order to have smooth variations in synthetic hurricane tracks and major storm parameters, additional model runs and later populating the results into the database are necessary. These were demonstrated during hindcasting hurricanes Camille and Katrina (Figure 6b). The optimum number of model simulations which need to be added to the existing data base can be determined based on sensitivity analyses. In addition to that, a spatial interpolation scheme must be developed to correlate among storm surge heights and hurricane parameters. For spatial interpolation, the Surge Response Function algorithm, recently developed at Texas A\&M University (Irish et al., 2008) may be incorporated in the SSFT. With this enhanced algorithm operating on a robust database, the present SSFT can be operational and useful to the emergency managers and planners. Using this SSFT as a decision aid, the emergency personnel can quickly forecast local storm surge along the coast of Mississippi. This will allow them to make quantitative and objective decisions by evaluating "what-if-scenarios" quickly after each advisory is issued and starting two to three days ahead of the landfall.

\section{ACKNOWLEDGEMENT}

The Department of Homeland Security (DHS) provided research fund to their Centre for Natural Disasters, Coastal Infrastructure, and Emergency Management (NDCIEM) at Jackson State University (JSU) to conduct this study. URS Corporation in Tallahassee, FL and Engineer Research and Development Center (ERDC) in Vicksburg, MS provided hurricane data and simulation results which were used in the SSFT database. Dr. Donald Resio of ERDC was very helpful in mentoring and guiding. 


\section{REFERENCES}

Fleming, J.G., C.W. Fulcher, R.A. Luettich, B.D. Estrade, G.D. Allen, and H.S. Winer. 2007. A real time storm surge forecasting system using ADCIRC. Estuarine and Coastal Modeling Congress 2007, 893-912.

Holland, G.J. 1980. An analytic model of the wind and pressure profiles in hurricanes. Monthly Weather Review, 108(8):1212-1218.

Irish, J., D. Resio, and J. Ratcliff. 2008. The influence of storm size on hurricane surge. Journal of Physical Oceanography, 38(9): 203-2013.

Mattocks, C. and C. Forbes. 2008. A real-time, event-triggered storm surge forecasting system for the state of North Carolina. Ocean Modeling, 25:95-119.

Niedoroda, A.W., D.T.Resio, G.R.Toro, D.Divoky, H.S.Das, and C.W.Reed. 2010. The role of wave set-up during extreme storms. Ocean Engineering, 37: 82-90

Resio, D.T., S.J. Boc, L. Borgman, V. Cardone, A. Cox, W.R. Dally, R.G. Dean, D. Divoky, E. Hirsh, J.L. Irish, D. Levinson, A. Niedoroda, M.D. Powell, J.J. Ratcliff, V.Stutts, J. Suhada, G.R. Toro, and P.J. Vickery. 2007. White Paper on Estimating Hurricane Inundation Probabilities. Consulting Report prepared by USACE for FEMA.

Westerink, J.J. and R.A. Luettich. 1991. Tide and storm surge predictions in the Gulf of Mexico using model ADCIRC-2D, Report to the U.S. Army Engineer Waterways Experiment Station, July, 1991. 